\title{
ABSTRACTS
}

\section{AN EXPERIMENTAL STUDY OF CHILDREN'S BEHAVIOR IN FAILURE}

by

\author{
Takano, Seijun
}

Tokyo University of Education

The importance of failure in the daily life of individual and personality development are recognized by many students and investigators. The experimental study of the effects of failure on subsequent activity is, however, extremely meager. Therefore, the present study is an attempt to know how children behave in the failure situations. It is, further, the purpose of the investigation to determine whether children who show undesirable responses in the face of failure may be made, and to modify the children's behavior by the special experiences.

The numbers of the subjects of the experiment were about ninty children between the age of 7years3 months and 10years-3months, including equal number of both sexes.

In step 1, all subjects were given a failure experience, and the subjects' responses were observed by the examiner through a one-side screen and recorded. On the basis of the results, the subjects were classified into three same quality groups; success group, failure group, and control group. In step 2, these groups were given each differential experiences. And in step 3, all subjects of all groups were observed again how they respond such a failure situations as in step 1.
The children's responses in failure, were roughly distinguished "the behaviors on the problem solving" from "the unrelated behaviors on it", and each of them was devided into several subcategories. After that, the responses which the subjects showed in step 3 were compared with them in the first failure situation, and the states of modification in those responses were examined.

The diagnostic value of these experiments shown in that they were able to differentiate clearly those subjects who behaved in an undesirable manner from those subjects who did not by "the Persistence Standard Score" (as defined in this study).

As the result, it is found that the correlation between Persistence Standard Score with I. $Q$. is ( $r$ $\Rightarrow 0.178$, with introversion-extroversion is $(r=)$ 2.66, and with the Otomo's neurotic standard is ( $r$ $\Rightarrow$ 8.11. Further, it seems to indicate that the failure experience, generally, make to decrease the subjects' Persistence Standard Score or desirable responses, while the success make to increase them. The variances were statistically significant.

Lastly some theoretical consideration of this modification in behavior was attempted. 